\title{
REVISTA BRASIEIRA DE
}

AGRICULTURA IRRIGADA

Revista Brasileira de Agricultura Irrigada v.7, nº. 5, p 317 - 329, 2013

ISSN 1982-7679 (On-line)

Fortaleza, CE, INOVAGRI - http://www.inovagri.org.br

DOI: $10.7127 /$ rbai.v7n500196

Protocolo 196.13 - 16/07/2013 Aprovado em 28/10/2013

\section{CARACTERIZAÇÃO HIDRÁULICA DE GOTEJADORES EM CONDIÇÃO SUPERFICIAL E SUBSUPERFICIAL}

\author{
Fernando Nobre Cunha ${ }^{1}$; Nelmício Furtado da Silva ${ }^{1}$; Renato Campos de \\ Oliveira $^{2}$; Marconi Batista Teixeira ${ }^{3}$; José Joaquim de Carvalho ${ }^{4}$; Raimundo \\ Rodrigues Gomes Filho ${ }^{5}$
}

\begin{abstract}
RESUMO
Na irrigação localizada, a uniformidade de aplicação de água ao longo da linha lateral está intimamente relacionada à variação de vazão dos emissores; deste modo o presente trabalho teve como objetivo avaliar os distúrbios de vazão em irrigação localizada, sob condição de gotejo subsuperficial e superficial (vazão crescente e decrescente). $\mathrm{O}$ experimento foi desenvolvido em uma casa de vegetação instalada na área experimental do IF Goiano Câmpus Rio Verde. Sobre uma bancada de ensaios foram instalados 20 recipientes de PVC com $0,1 \mathrm{~m}$ de diâmetro e 0,6 $\mathrm{m}$ de altura, contendo cada recipiente um gotejador enterrado a 0,2 $\mathrm{m}$ de profundidade para permitir o monitoramento da vazão em condições subsuperficiais. Utilizou-se solo de textura argilosa para preencher os recipientes. O delineamento experimental foi inteiramente casualizado, utilizando-se dois modelos de gotejadores com dez repetições (gotejadores) em cada linha lateral. Utilizaram-se as pressões de 0,4, 0,6, 0,8, 1,0 e 1,2 bar (modelo 1) e pressões de $0,5,1,0,1,5,2,0,2,5$ e 3,0 bar (modelo 2) para confecção das curvas. A vazão média dos gotejadores reduziu em função de se trabalhar em condições subsuperficiais enquanto que em situação superficial o comportamento hidráulico foi excelente. $\mathrm{O}$ modelo 2 de gotejador foi mais suscetível a distúrbios de vazão do que o modelo 1 . O sentido (crescente ou decrescente) e a pressão de serviço
\end{abstract}

\footnotetext{
${ }^{1}$ Engenheiro Agrônomo, Mestrando em Ciências Agrárias, Instituto Federal de Educação, Ciência e Tecnologia - Câmpus Rio Verde. Rodovia Sul Goiana km 01, CEP 75901-970, Rio Verde, GO. Fone: (64) 9235-8631. e-mail: fernandonobrecunha@ hotmail.com

2 Acadêmico de Agronomia Instituto Federal de Educação, Ciência e Tecnologia - Câmpus Rio Verde. Rodovia Sul Goiana km 01, CEP 75901-970, Rio Verde, GO.

${ }^{3}$ Engenheiro Agrônomo, Doutor em Agronomia, Professor, Instituto Federal de Educação, Ciência e Tecnologia -Câmpus Rio Verde. Rodovia Sul Goiana km 01, CEP 75901-970, Rio Verde, GO.

${ }^{4}$ Pós-doutorando em Ciências Agrárias, Instituto Federal de Educação, Ciência e Tecnologia Câmpus Rio Verde. Rodovia Sul Goiana km 01, CEP 75901-970, Rio Verde, GO.

5 Engenheiro Agrônomo, Doutor em Engenharia Agrícola, Professor Adjunto Universidade Federal de Sergipe -UFS, Aracaju, SE.
} 
têm influência direta sobre a uniformidade de aplicação, podendo ser de até $8 \%$, o que ocorre durante a pressurização do sistema e da regulagem da pressão.

Palavras-chave: vazão média, obstrução, histerese.

\title{
HYDRAULIC CHARACTERIZATION OF DRIPPERS UNDER CONDITION SURFACE AND SUBSURFACE
}

\begin{abstract}
The uniformity of water application along the lateral line is closely related to the variation of flow emitters in localized irrigation, so the present study aimed to evaluate disorders of flow in irrigation, on condition of subsurface and surface drip (flow ascending and descending). The experiment was conducted in a greenhouse installed in the experimental area IF Goiano Câmpus Rio Verde. 20 PVC containers with $0.1 \mathrm{~m}$ of diameter and $0.6 \mathrm{~m}$ in height were installed on a test bench. Each container had a dripper buried at $0.2 \mathrm{~m}$ depth to allow monitoring of subsurface flow conditions. Clay soil was used to fill the containers. The experimental design was completely randomized, using two models of drippers with 10 replications (drippers) on each sideline. The pressures used were 0.4, 0.6, $0.8,1.0$ and 1.2 bar (model 1) and pressures of 0.5, 1.0, 1.5, 2.0, 2.5 and 3.0 bar (model 2) for making curves. The average flow of the drippers decreased during the working in conditions of subsurface, while the behavior hydraulic was excellent in the conditions of surface. The dripper model 2 was more susceptible to disturbance flow than the model 1 . The direction (ascending or descending) and service pressure have a direct influence on the uniformity of application, can be up to $8 \%$, which occurs during system pressurization and pressure control.
\end{abstract}

Keywords: average flow, obstruction, hysteresis.

\section{INTRODUÇÃO}

A irrigação é o conjunto de técnicas destinadas a deslocar a água no tempo ou no espaço para modificar as possibilidades agrícolas de cada região, visando corrigir a distribuição natural das chuvas, proporcionando alcançar a máxima produção (WERNECK et al., 2009). Logo, a irrigação na agricultura deve ser entendida não somente como um seguro contra secas ou veranicos, mas como uma técnica que dê condições para que o material genético expresse em campo todo o seu potencial produtivo (HERNANDEZ, 2004).

No dimensionamento de sistemas de irrigação localizada, deve-se considerar a variabilidade existente entre gotejadores, decorrente do processo de fabricação. Outro ponto importante é que o sistema pode apresentar distúrbios de vazão ao longo do tempo em função da qualidade de água e do manejo de irrigação utilizado (COELHO, 2007a).

As características hidráulicas dos emissores em irrigação localizada constituem-se na relação vazão versus pressão na entrada, na uniformidade de fabricação, na uniformidade de distribuição da água (NASCIMENTO, 1999), ocorrendo menor variação da carga hidráulica na linha de derivação em declive, para maiores valores de uniformidade 
de emissão (SAAD \& MARCUSSI, 2006).

Enciso et al. (2007), Barros et al. (2009), observam como causas das variações da eficiência de irrigar por gotejamento em subsuperfície as formas de localização dos equipamentos (emissores) no interior do perfil do solo (profundidade), a distância entre plantas e equipamentos, devido o entupimento dos emissores por intrusão de raízes.

A manutenção do sistema de irrigação no subsolo (no interior do perfil do solo) é mais difícil, pois a taxa de vazão de cada emissor pode ser afetada pelas propriedades do solo (GIL et al., 2008), além da possibilidade de entupimento por partículas sólidas e raízes; em pesquisas realizadas com entupimentos decorrentes de partículas sólidas na malha hidráulica, Coelho et al. (2007b) observaram que a obstrução total foi predominante em relação à parcial (afeta uma porção dos emissores igualmente).

A utilização de sistemas de irrigação mais eficientes é uma meta a ser atingida na agricultura irrigada; porém, por melhor que seja o sistema de irrigação, a distribuição da água aplicada dificilmente será plenamente uniforme, e a mensuração dessa variabilidade é fundamental na avaliação do desempenho da irrigação (SILVA et al., 2004). A avaliação da irrigação é uma importante etapa para obter as informações relacionadas à eficiência de uso da água do sistema de irrigação, perdas durante a aplicação e uniformidade de distribuição de água, funcionamento real do sistema (vazão, pressão, lâmina, entupimento, etc.) e necessidade de manutenção (MANTOVANI et al., 2009). O presente trabalho teve como objetivo avaliar os distúrbios de vazão em irrigação localizada, sob condição de gotejo subsuperficial e superficial (vazão crescente e decrescente).

\section{MATERIAL E MÉTODOS}

O experimento foi realizado em uma casa de vegetação instalada na área experimental do IFGoiano - Câmpus Rio Verde. A casa de vegetação é constituída de cobertura de filme plástico polietileno transparente, de 150 micras e laterais fechadas, com tela tipo sombrite com $30 \%$ de interceptação.

O delineamento experimental foi inteiramente casualizado, utilizando-se dois modelos de gotejadores com dez repetições (gotejadores) em cada linha lateral. Utilizaram-se as pressões de $0,4,0,6,0,8,1,0$ e 1,2 bar (modelo 1 ) e pressões de $0,5,1,0,1,5,2,0,2,5$ e 3,0 bar (modelo 2) para confecção das curvas.

A unidade experimental (dispositivo de medição de vazão) foi constituída por 20 recipientes de PVC com dimensões em metros: 0,1 x 0,6 m (diâmetro e comprimento), contendo cada recipiente um gotejador a $0,20 \mathrm{~m}$ de profundidade dentro do dispositivo (Figura 1).

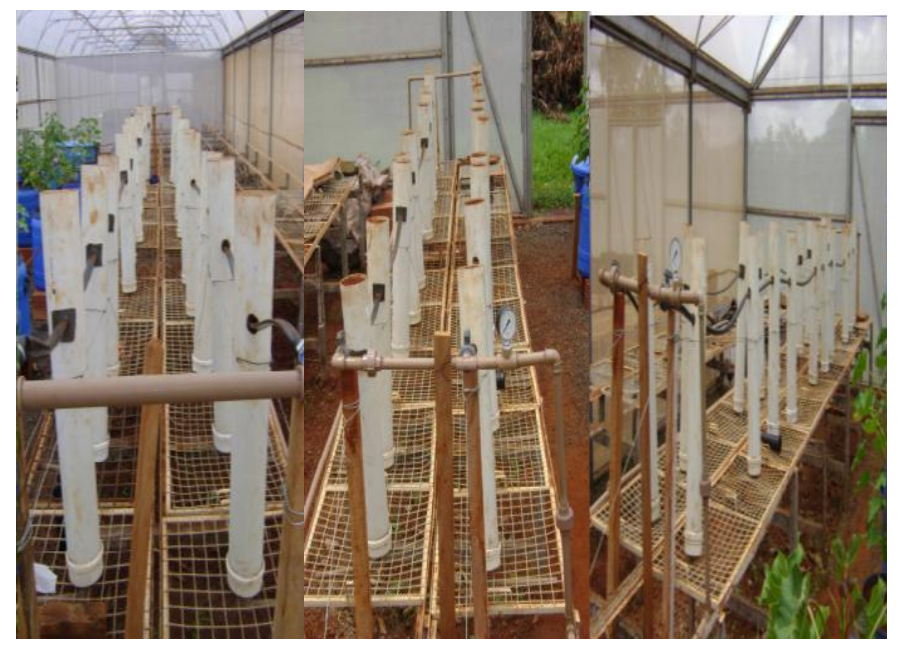

Figura 1. Fotos ilustrativas do sistema de irrigação e os tratamentos utilizados. 
Foram utilizados dois modelos de tubos gotejadores (modelo 1 e 2) autocompensantes com vazão nominal de 1,0 e $1,5 \mathrm{~L} \mathrm{~h}^{-1}$ diâmetro nominal $16 \mathrm{~mm}$, diâmetro interno 13 e 13,8 mm, pressão de operação 100 a $350 \quad \mathrm{kPa}$ e espaçamento entre emissores de $1 \mathrm{~m}$, sendo que os recipientes foram acoplados aos gotejadores ao longo de duas linhas laterais. Foi acoplado à bancada de ensaios um reservatório de $250 \mathrm{~L}$. Inicialmente, foi realizada uma leitura de vazão para cada gotejador inserido em cada uma das linhas gotejadoras, para caracterizar o funcionamento dos mesmos.

A água, após passar através dos gotejadores selecionados ao longo da linha lateral foi recolhida pelo dispositivo de medição de vazão permitindo, assim, o monitoramento da vazão e a caracterização hidráulica dos tubos gotejadores.

À entrada das linhas gotejadoras foi instalada uma tomada de pressão, permitindo que a cada medição de vazão a pressão fosse checada e, se necessária, ajustada àquela pré-estabelecida. Para a medição da pressão de serviço, à entrada da linha de emissores, foi utilizado um manômetro de Bourdon com faixa de leitura de 0 $-7 \mathrm{kgf} \mathrm{cm}^{-2}$. Durante todo o período do ensaio foram realizadas leituras de temperatura da água no reservatório de captação.

Para obter-se maior exatidão foi utilizado o método gravimétrico para a determinação do volume coletado de cada emissor, expressaram-se os valores de vazão em $\mathrm{L} \mathrm{h}^{-1}$, utilizando para tal uma balança de precisão certificada.

Os procedimentos para leitura individual da vazão dos gotejadores consistiram da pressurização do sistema, posicionamento de recipientes (capacidade de 1 L) sob os respectivos gotejadores com uma defasagem de 5 segundos, retirada sequencial dos recipientes após 5 minutos com defasagem de 5 segundos, medição do volume coletado e tabulação dos dados. O monitoramento da vazão dos gotejadores $\left(\mathrm{L} \mathrm{h}^{-1}\right)$ permitiu a obtenção da vazão média dos gotejadores, utilizando-se a equação 1 .

$$
q=\frac{M}{1000 \times t} 60
$$

em que:

$q$ - vazão do gotejador, $\mathrm{L} \mathrm{h}^{-1}$;

$M$ - massa de água coletada, g; e $t$ - tempo de coleta, min.

Depois de tabulados os dados de vazão foram efetuados os cálculos de uniformidade de Christiansen (CUC) e de distribuição (CUD), grau de entupimento (GE) e coeficiente de variação $(\mathrm{CV})$ destacados nas equações 2 a 5 .

$$
C U C=100\left\{1-\frac{\sum_{i=1}^{n}\left|X_{i}-\bar{X}\right|}{n \cdot \bar{X}}\right\}
$$

CUC = coeficiente de uniformidade de Christiansen (CHRISTIANSEN, 1942), em \%.

$$
C U D=100\left(\frac{X_{25 \%}}{\bar{X}}\right)
$$

CUD = coeficiente de uniformidade de distribuição (CRIDDLE et al., 1956), em \%.

$$
G E=\left(1-\frac{q_{\text {usado }}}{q_{\text {novo }}}\right) 100
$$

$\mathrm{GE}=$ grau de entupimento, em $\%$. 


$$
C V=100\left(\frac{S}{\bar{X}}\right)
$$

$\mathrm{CV}=$ coeficiente de variação, em $\%$.

em que:

$X_{i}=$ vazão de cada gotejador, em $\mathrm{L} \mathrm{h}^{-1}$;

$\bar{X}=$ vazão média dos gotejadores, em $\mathrm{L} \mathrm{h}^{-1}$;

$n$ = número de gotejadores observados;

$S=$ desvio-padrão dos dados de vazão, $\mathrm{em} \mathrm{L} \mathrm{h}^{-1}$;

$X_{25 \%}=$ média de $25 \%$ do total de gotejadores, com as menores vazões, em $\mathrm{L} \mathrm{h}^{-1}$;

qusado - vazão do gotejador usado $\left(\mathrm{L} \mathrm{h}^{-1}\right)$; e

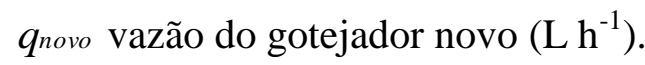

Para avaliação dos coeficientes de uniformidade foram utilizadas as classificações dos valores encontrados propostas na literatura para cada modelo - CUC e CUD (ASAE, 2003). Os dados obtidos foram submetidos à análise de variância pelo teste $\mathrm{F}$ ao nível de 0,05 de probabilidade, e em casos de significância, foi realizada a análise de regressão polinomial linear e quadrática em função das pressões de serviço para cada coeficiente.

\section{RESULTADOS E DISCUSSÃO}

Nas Figuras 2 e 3 podem ser observadas as vazões médias dos dois modelos de tubos gotejadores ensaiados para diferentes valores de pressão em ordem crescente e decrescente. Ambos os modelos de gotejadores ensaiados têm suas vazões mais próxima da vazão recomendada pelo fabricante (modelo $1=1,0 \mathrm{~L} \mathrm{~h}^{-1}$ e modelo 2 $=1,5 \mathrm{~L} \mathrm{~h}^{-1}$ ) quando em situação superficial. A vazão, de ambos os gotejadores, reduziu em condições subsuperficiais comprometendo o funcionamento dos mesmos para um adequado manejo de irrigação conforme a pressão de serviço recomendada pelos fabricantes (PS $=1,0$ bar).
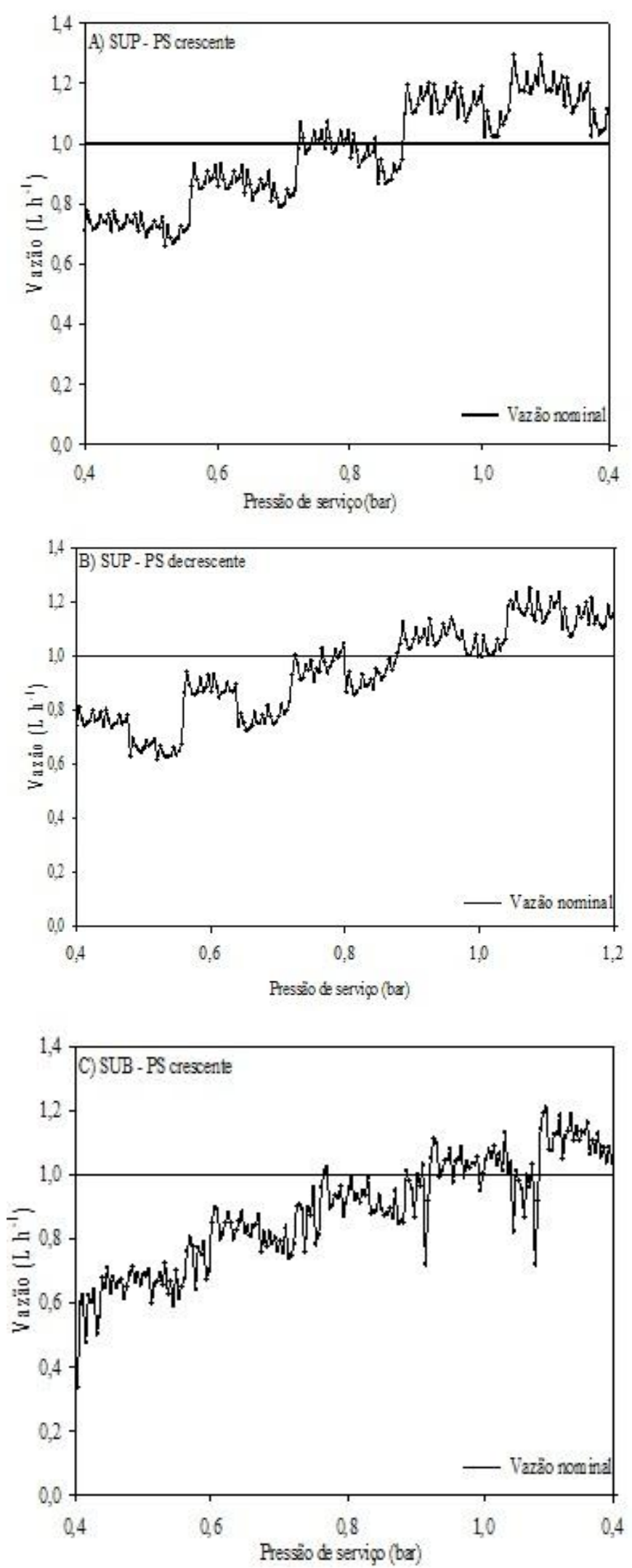


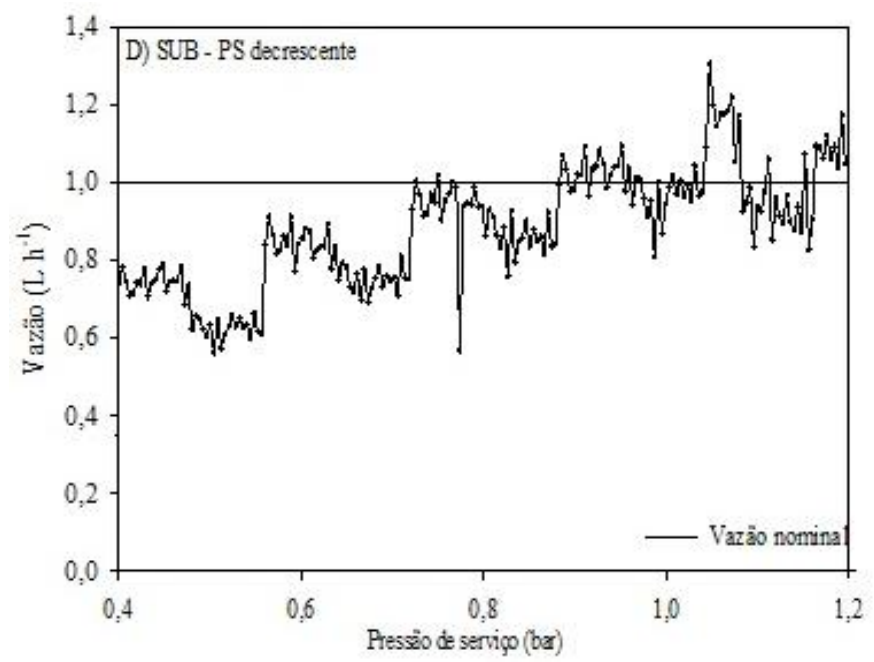

Figura 2. Curva de vazão do modelo 1 de tubo gotejador em condição superficial (A e B) e subsuperficial ( $\mathrm{C}$ e $\mathrm{D}$ ) ensaiado em diferentes pressões de serviço em ordem crescente $(\mathrm{A}$ e C $)$ e decrescente (B e D). PS - Pressão de serviço; SUB Subsuperficial; SUP - Superficial.
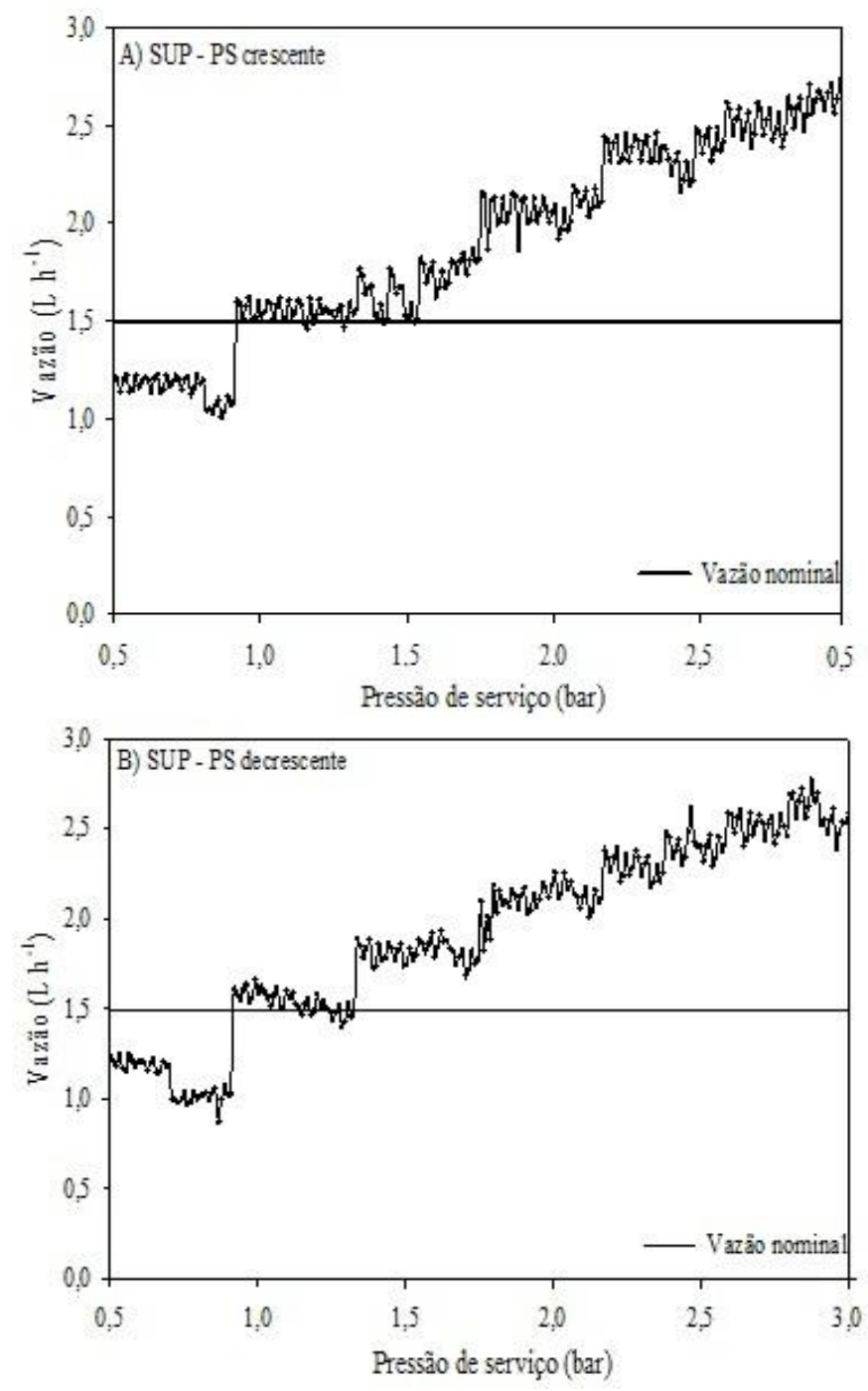
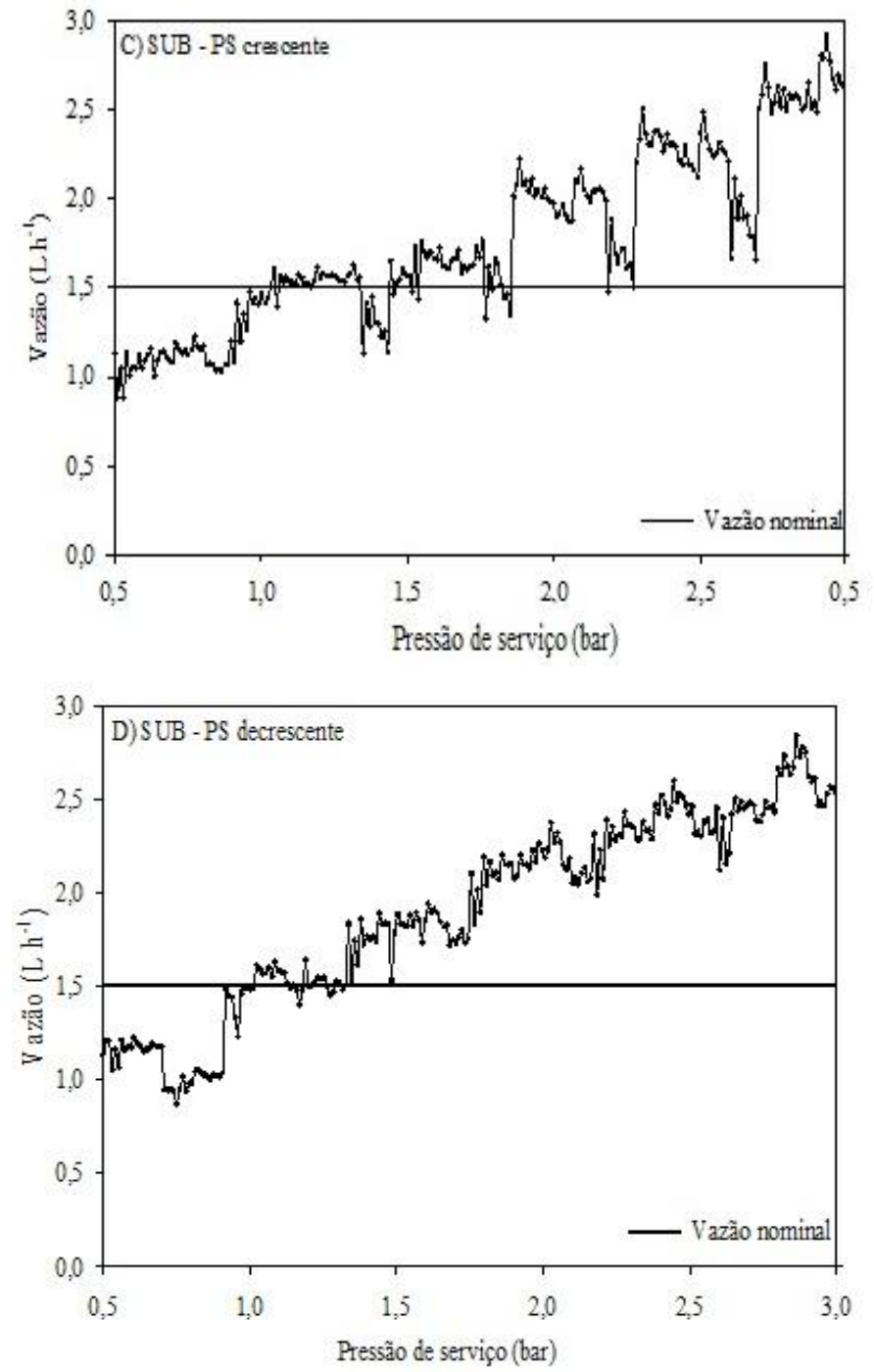

Figura 3. Curva de vazão do modelo 2 de tubo gotejador em condição superficial $\left(\begin{array}{lll}A & \text { e } & B\end{array}\right)$ e subsuperficial ( $\mathrm{C}$ e $\mathrm{D})$ ensaiado em diferentes pressões de serviço em ordem crescente (A e C) e decrescente (B e D). PS - Pressão de serviço; SUB Subsuperficial; SUP - Superficial.

Em condições subsuperficiais o modelo 1 de gotejadores apresentou CV superior a $10 \%$ para o menor e maior valores de pressão ensaiada, mostrando que para baixas e altas pressões esses emissores apresentam distúrbios de vazão ao longo da linha lateral. Para a condição superficial os valores de $\mathrm{CV}$ foram bons para toda a faixa de pressão ensaiada, exceto nas menores pressões e curva decrescente que evidenciou uma maior variação, sendo o modelo 1 e modelo 2, 71,52 e 
44,52\% superior à vazão crescente, respectivamente (Tabela 1 ).

Um sistema de irrigação localizada bem projetado permite que se obtenha uniformidade de aplicação de água acima de $90 \%$, o que se considera um ótimo índice para esse sistema; entretanto, com o seu intensivo uso, observa-se uma diminuição na uniformidade de emissão e um aumento no coeficiente de variação de fabricação (CVf), ao longo do tempo, ocasionados por diversos fatores (TEIXEIRA, 2006).

Tabela 1.Coeficiente de variação de vazão do modelo 1 de tubo gotejador ensaiados para diferentes valores de pressão em ordem crescente e decrescente.

\begin{tabular}{|c|c|c|c|c|c|c|c|}
\hline \multicolumn{8}{|c|}{ Modelo 1} \\
\hline \multirow{2}{*}{ Posição } & \multirow{2}{*}{ Curva } & \multicolumn{6}{|c|}{ Pressão média nominal (bar) } \\
\hline & & 0,4 & 0,6 & 0,8 & 1,0 & & 2 \\
\hline \multirow{3}{*}{ Subsuperficial } & & \multicolumn{6}{|c|}{$\mathrm{CV}(\%)$} \\
\hline & Crescente & 10,91 & 6,21 & 4,35 & 5,66 & \multicolumn{2}{|c|}{8,86} \\
\hline & Decrescente & 10,15 & 7,30 & 5,01 & 4,36 & \multicolumn{2}{|c|}{11,7} \\
\hline \multirow{2}{*}{ Superficial } & Crescente & 2,60 & 3,29 & 4,85 & 3,81 & \multicolumn{2}{|c|}{5,68} \\
\hline & Decrescente & 9,13 & 7,81 & 4,36 & 2,10 & \multicolumn{2}{|c|}{2,54} \\
\hline \multicolumn{8}{|c|}{ Modelo 2} \\
\hline \multirow{2}{*}{ Posição } & \multirow{2}{*}{ Curva } & \multicolumn{6}{|c|}{ Pressão média nominal (bar) } \\
\hline & & 0,5 & 1,0 & 1,5 & 2,0 & 2,5 & 3,0 \\
\hline & & \multicolumn{6}{|c|}{$\mathrm{CV}(\%)$} \\
\hline \multirow{2}{*}{ Subsuperficial } & Crescente & 4,69 & 5,70 & 10,69 & 13,36 & 14,25 & 15,14 \\
\hline & Decrescente & 9,92 & 4,08 & 3,33 & 3,98 & 4,20 & 6,00 \\
\hline \multirow{2}{*}{ Superficial } & Crescente & 5,37 & 0,62 & 5,57 & 1,83 & 2,73 & 2,50 \\
\hline & Decrescente & 9,68 & 3,45 & 2,06 & 2,72 & 2,95 & 2,89 \\
\hline
\end{tabular}

Em condições subsuperficiais o modelo 2 de gotejadores apresentou CV superior a $10 \%$ para valores de que para altas pressões esses emissores apresentam distúrbios de vazão ao longo da linha lateral. Para condição superficial os valores de CV foram também bons para toda a faixa de pressão ensaiada (Tabela 1). Para não prejudicar a uniformidade de aplicação de água, ASAE (2003) recomenda que a variação da vazão máxima dos gotejadores seja de $10 \%$ em todo o sistema de irrigação. O Coeficiente de uniformidade de Christiansen (CUC) para o modelo 1, segundo a classificação sugerida por Mantovani (2001), é considerado excelente (>90\%) para todas as pressões médias nominais, tanto na posição superficial e subsuperficial, quanto à curva crescente e decrescente (Figura 4).
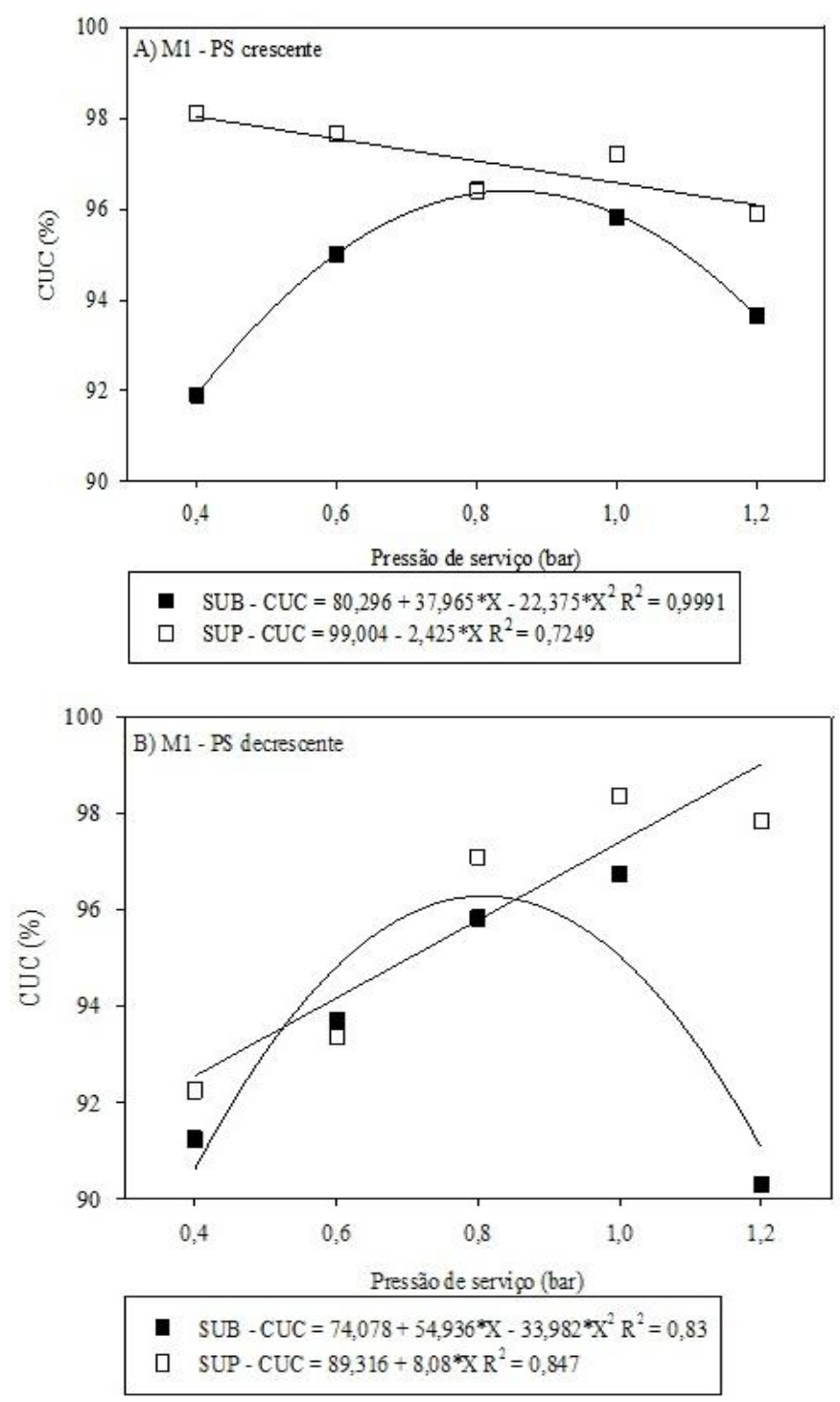

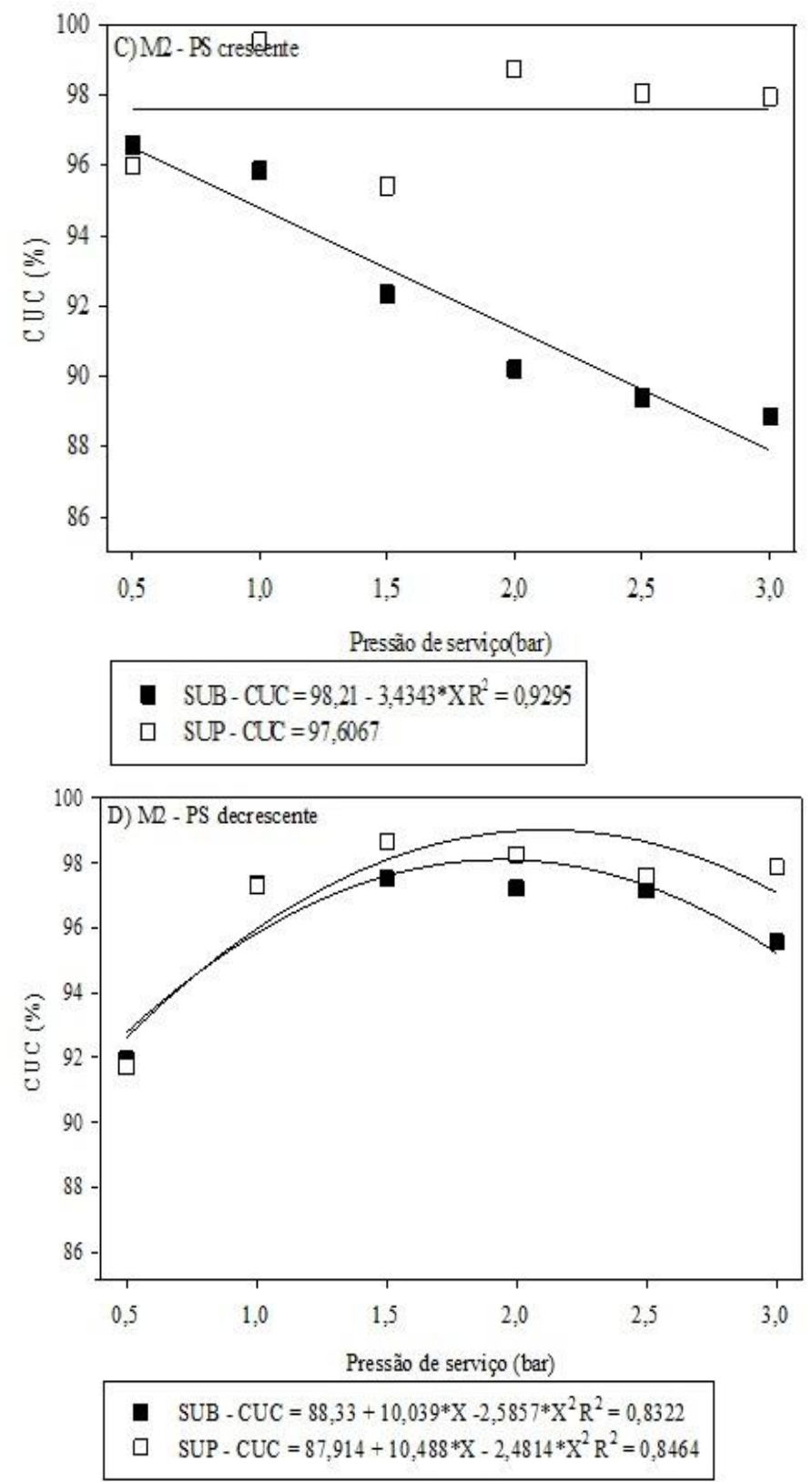

Figura 4. Coeficiente de Uniformidade de Christiansen (CUC) do modelo 1 de tubo gotejador (A e B) e do modelo 2 (C e D), ensaiados em diferentes pressões de serviço em ordem crescente (A e C) e decrescente (B e D).PS - Pressão de serviço; SUB Subsuperficial; SUP - Superficial.

O CUC para o modelo 2, segundo a mesma classificação, é considerado excelente (>90\%) para praticamente todas as pressões médias nominais, tanto na posição superficial e subsuperficial, quanto à curva crescente e decrescente, exceto para as pressões médias nominais de 2,5 e 3,0 bar, na posição subsuperficial e em curva crescente, que apresentaram valores abaixo de 90\% (Figura 4), e logo não demonstraram o mesmo desempenho anterior, deste modo sendo classificado como bom $(80-90 \%)$.

Os modelos 1 e 2 demonstraram que em ambos os casos o sentido da pressão (crescente e decrescente) tem influência sobre a uniformidade de aplicação, podendo ser este efeito de até $8 \%$, indicando uma dificuldade ou até mesmo uma incerteza na obtenção de uniformidades desejadas, que pode ocorrer simplesmente com a maneira com a qual ocorre a pressurização do sistema e da regulagem da pressão.

A vazão quando analisada individualmente reforça este desvio que pode ser agravado dependendo da precisão do manômetro, pois quando foram consideradas mais casas decimais para estabelecimento da pressão, menor foi à diferença de uniformidade obtida, enquanto que reduzindo o número de casas decimais, ou aumentando a escala esta diferença chegou a $13,6 \%$.

O coeficiente de uniformidade de distribuição - CUD é indicado mesmo quando se têm valores altos de CUC (acima de 85\%) (VALNIR JÚNIOR et al., 2011). O CUD para o modelo 1, para todas as pressões médias nominais, tanto na posição superficial e subsuperficial, quanto à curva crescente e decrescente, são considerados bons (Figura 5).

O CUD para o modelo 2, para boa parte das pressões médias nominais, tanto na posição superficial e subsuperficial, quanto à curva crescente e decrescente, são considerados bons, no entanto para as pressões médias nominais de 2,5 e 3,0 bar, na posição subsuperficial e quanto a curva crescente observou-se, os valores de CUD de 78,79 e $77,70 \%$ respectivamente, considerados razoáveis (Figura 5). 

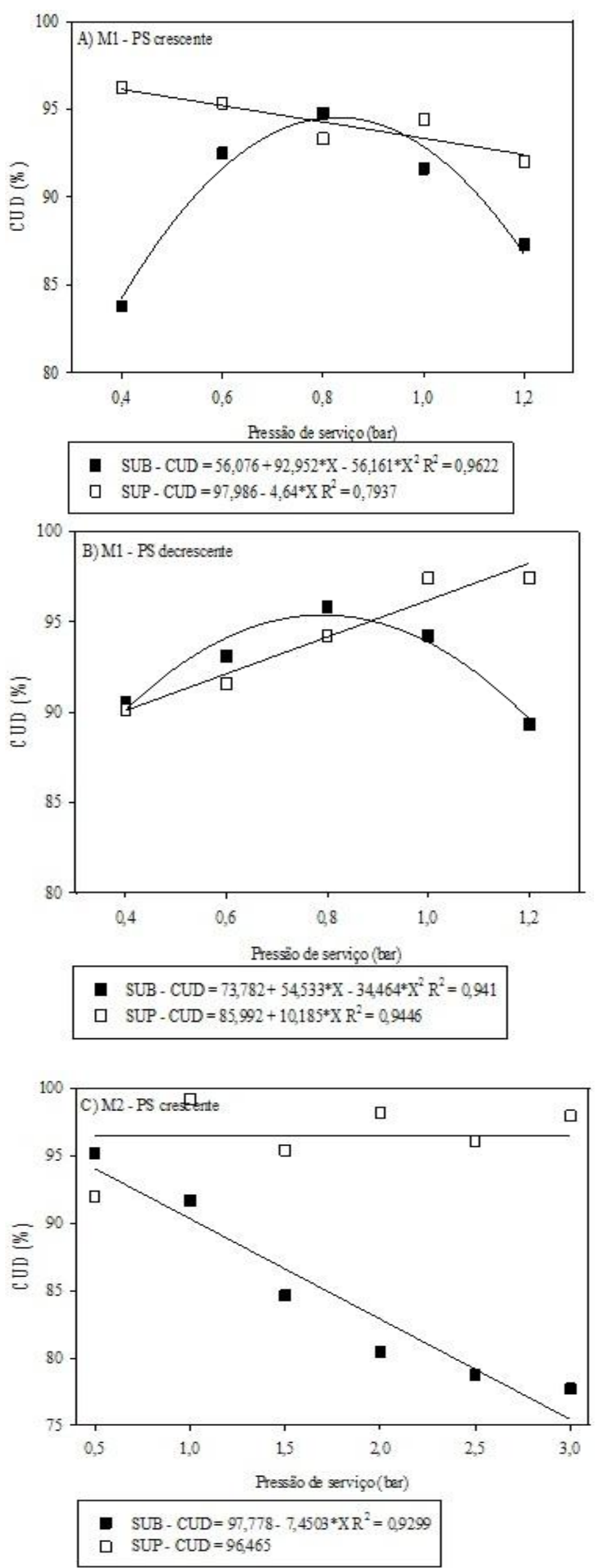

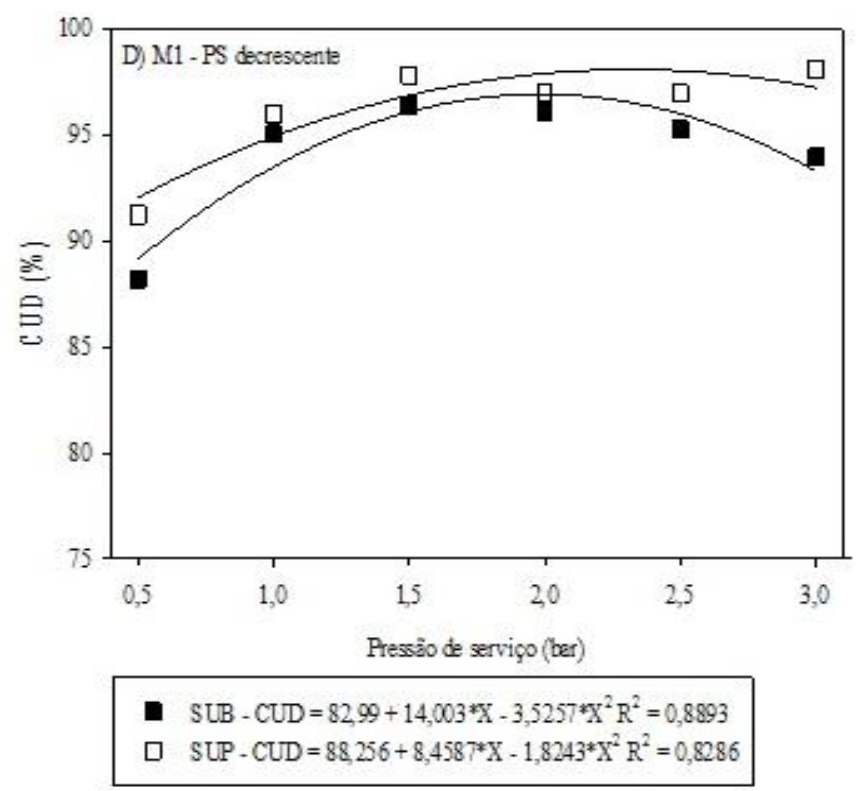

Figura 5. Coeficiente de Uniformidade de Distribuição (CUD) do modelo 1 de tubo gotejador (A e B) e do modelo 2 ( $\mathrm{C}$ e D), ensaiados em diferentes pressões de serviço em ordem crescente (A e C) e decrescente (B e D). PS - Pressão de serviço; SUB Subsuperficial; SUP - Superficial.

O grau de entupimento (GE) diminui com o aumento da pressão para o modelo 1 , o que persistiu até a pressão recomendada pelo fabricante (1,0 bar), entretanto a partir desta pressão, o GE passa a elevar-se conforme aumenta a pressão, e isto se mostrou da mesma maneira tanto em ordem crescente quanto em ordem decrescente. Em função dos pequenos diâmetros de orifício, o entupimento dos emissores configura-se como um dos principais problemas relacionados ao método (KELLER \& BLIESNER, 1990).

O maior GE foi de $36,82 \%$ e o menor foi de $1,37 \%$ observados na condição subsuperficial em ordem crescente e na pressão de 0,4 e 1,0 bar, respectivamente; já para a condição superficial o maior e menor valor do GE deu-se nas pressões de 0,4 e 0,8 bar, os quais foram de 27,4 e 2,45\%. Em ordem decrescente os valores de GE foram similares aos encontrados na ordem crescente, 
entretanto os melhores valores de GE, nesta condição $(0,5$ e $5,4 \%)$ ocorreram na pressão de 1,0 bar (Figura 6).

$\mathrm{O}$ entupimento parcial dos emissores, que se constitui o caso mais comumente encontrado em campo, apresenta o inconveniente adicional de não ser perceptível visualmente, o que retarda a tomada de ação para o equacionamento do problema; diferentes gotejadores apresentam graus de suscetibilidade diversos ao entupimento, seja em função de características construtivas, hidráulicas ou de mecanismos próprios de autolimpeza (RESENDE et al., 2000).
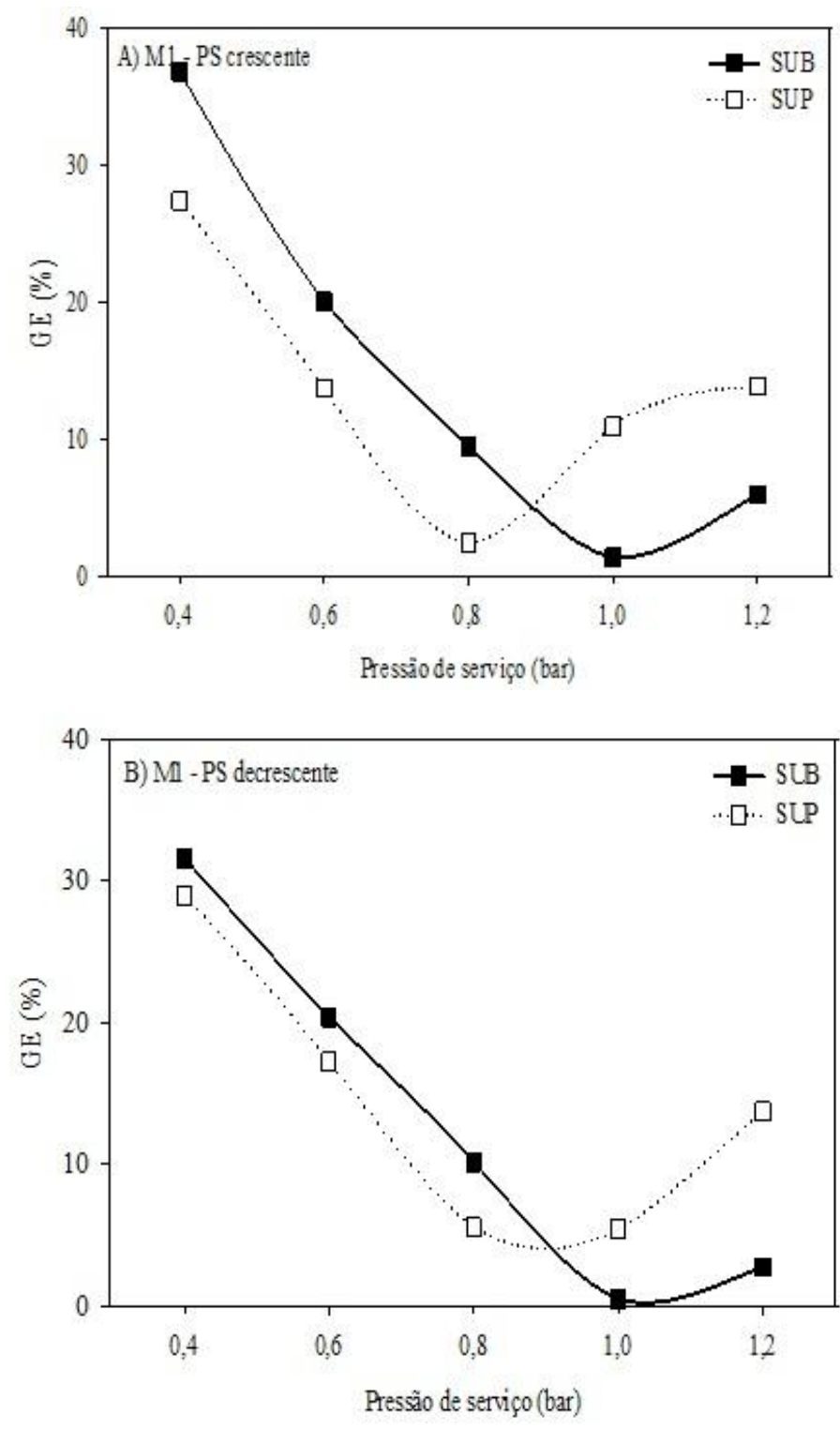
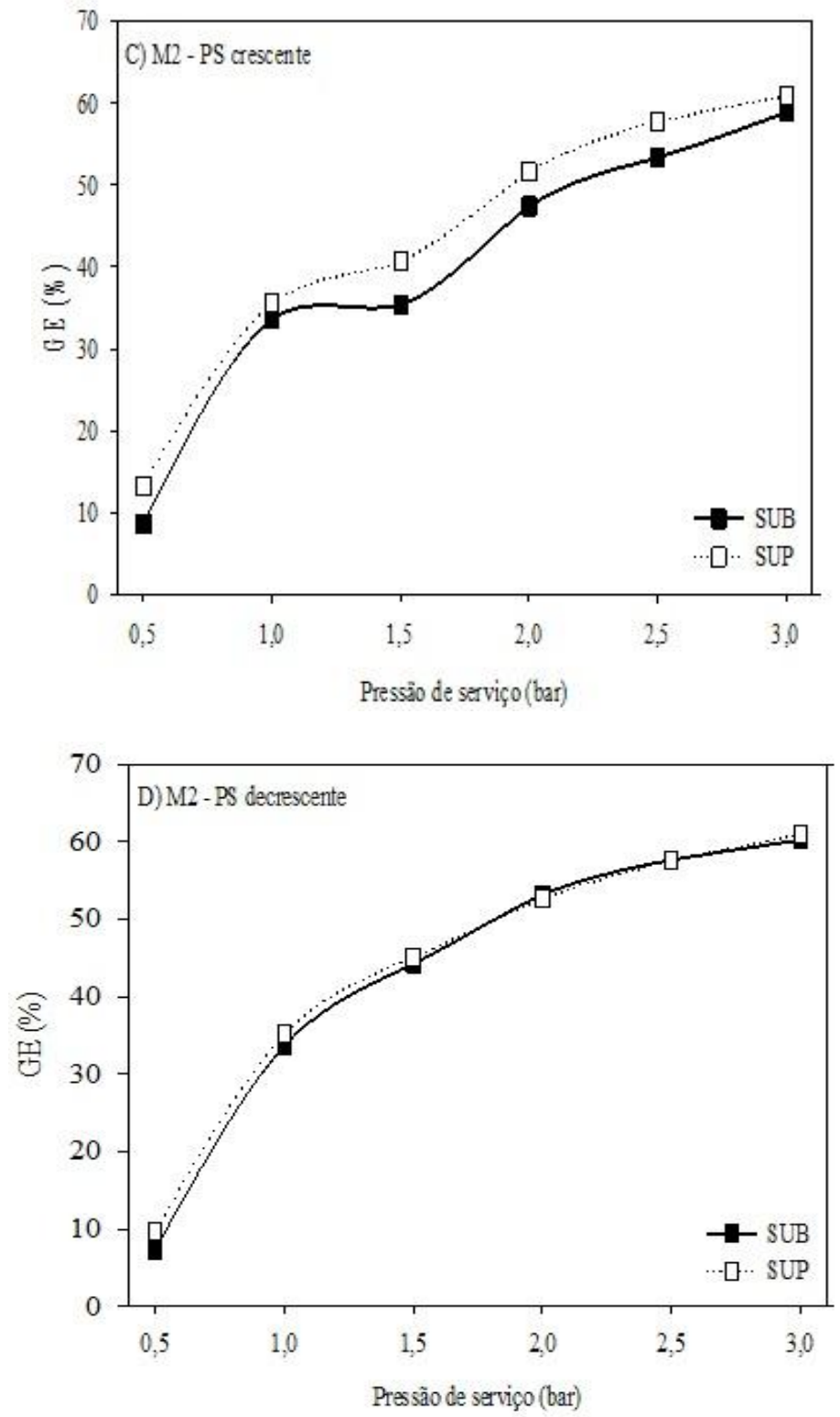

Figura 6. Grau de entupimento (GE) do modelo 1 de tubo gotejador (A e B) e do modelo 2 (C e D), ensaiados em diferentes pressões de serviço em ordem crescente (A e C) e decrescente (B e D). PS - Pressão de serviço; SUB - Subsuperficial; SUP - Superficial.

O GE para o modelo 2 elevou-se com o aumento da pressão, em ambas as condições (crescente e decrescente); os valores mais baixos de GE foram observados na pressão de 0,5 bar, os quais foram de 8,57 e $13,23 \%$ (subsuperficial e superficial), na condição crescente, 7,20 e 9,53\% (subsuperficial e superficial) na condição decrescente; já os valores mais altos de GE foram observados na pressão de 3,0 bar, os quais foram 
de 58,92 e $60,95 \%$ (subsuperficial e superficial), na condição crescente, 60,21 e $60,92 \%$ (subsuperficial e superficial) na condição decrescente (Figura 6).

Um efeito bastante negativo do entupimento, relatado por vários autores, consiste na redução da vazão dos gotejadores. Já no que se refere ao manejo do sistema de aplicação, uma consequência direta da baixa uniformidade de aplicação de água é o aumento do volume aplicado, uma vez que o aplicador, ao constatar a diminuição da vazão média dos gotejadores, pelo efeito do entupimento, tem a tendência de aumentar o tempo de aplicação (CUNHA et al., 2006).

De maneira geral, tais gotejadores tenderam a apresentar redução de vazão quando enterrados. Quanto ao aspecto construtivo (barreiras físicas), nenhum dos gotejadores ensaiados (usualmente recomendados para irrigação por gotejamento subsuperficial) demonstrou possuir mecanismos que impeçam efetivamente a entrada de partículas sólidas em seu interior.

Para condição subsuperficial, a variação de pressão de serviço alterou drasticamente a vazão, comprometendo o adequado funcionamento de ambos os modelos de gotejadores para a pressão de serviço recomendada pelo fabricante. Além disso, pode-se observar que o modelo 2 de gotejador foi mais suscetível a distúrbios de vazão do que o modelo 1 .

\section{CONCLUSÕES}

A vazão média dos gotejadores reduziu em função de se trabalhar em condições subsuperficiais (presença de partículas sólidas argila, silte e areia), enquanto que em situação superficial o comportamento hidráulico foi excelente. $\mathrm{O}$ modelo 2 de gotejador foi mais suscetível a distúrbios de vazão do que o modelo 1.

O sentido (crescente ou decrescente) e a pressão de serviço têm influência direta sobre a uniformidade de aplicação, podendo ser de até $8 \%$, o que ocorre durante a pressurização do sistema e da regulagem da pressão.

O modelo 1 apresenta um menor grau de entupimento em condição superficial do que subsuperficialmente; já para o modelo 2 o grau de entupimento aumentou com o aumento da pressão, em ambas as condições (crescente e decrescente).

\section{REFERÊNCIAS BIBLIOGRÁFICAS}

ASAE - American Society of Agricultural Engineers.ASAE EP 405.Design and installation of microirrigation systems.In: ASAE Standsrds 2003. St. Joseph: ASAE. 2003. p.900-905.

BARROS, A.C.; FOLEGATTI, M.V.; SOUZA, C.F.; SANTORO, B.L. Distribuição de água no solo aplicado por gotejamento enterrado e superficial. Revista Brasileira de Engenharia Agrícola e Ambiental, v.13, n.6, p.700-707, 2009.

CHRISTIANSEN, J. E. Irrigation by Sprinkling. Berkeley: California Agricultural Station, 1942. 124 p. Bulletin, 670.

COELHO, R. D. Contribuições para a irrigação pressurizada no Brasil. 2007. 192 p. Livre-Docência - Escola Superior de Agricultura 
"Luiz de Queiroz", Universidade de São Paulo, Piracicaba. ESALQ, 2007a.

COELHO, R. D.; VILELA, L. A. A.; RESENDE, R. S.; TEIXEIRA, M. B.; SÁ, J. S. de. Entupimento de gotejadores em decorrência de pulsos de partículas sólidas na malha hidráulica. Irriga, v.12, p.108-122, 2007b.

CRIDDLE, W. D.; DAVIS, S.; PAIR, C. H.; SHOCKLEY, D. G. Methods for Evaluating Irrigation Systems.Washington DC: Soil Conservation Service - USDA, 1956. 24 p. AgriculturalHandbook, 82.

CUNHA, F. F. da, MATOS, A. T. de, BATISTA, R. O.; MONACO, P. A. L. Uniformidade de distribuição em sistemas de irrigação por gotejamento utilizando água residuária da despolpa dos frutos do cafeeiro. Acta Scientiarum. Agronomy, v. 28, n. 1, p. 143-147, 2006.

ENCISO, J.; JIFON, J.; WIEDENFELD, B. Subsurface drip irrigation of onions: Effects of drip tape emitter spacing on yield and quality. Agricultural Water Management, v. 92, n. 3, p. 126-130, 2007.

GIL, M.; SINOBAS, R.; JUANA, L.; SÁCHEZ, R.; LOSADA, A. Emitter discharge variability of subsurface drip irrigation in uniform soils: Effect on water-application uniformity. Irrigation

Science, v. 26, p. 451-458, 2008.

HERNANDEZ, F. B. T. Manejo da irrigação. 2004.

Disponível
http://www.irrigaterra.com.br/manejo.php.Acesso em: 28 ago. 2012.

KELLER, J.; BLIESNER, I.D.Sprinkler and trickle irrigation. New York: Van Nostrand Reinhold, 1990. 652p.

MANTOVAni, E. C. Avalia: Programa de Avaliação da Irrigação por Aspersão e Localizada. Viçosa, MG: UFV, 2001.

MANTOVANI, E. C.; BERNARDO, S.; PALARETTI, L. F. Irrigação: princípios e métodos. 2. ed., atual e ampliado. Viçosa, MG: UFV, 2009. 355 p.

NASCIMENTO, T. Caracterização Hidráulica do Microaspersor Rain-Bird Qn-141. Revista Brasileira de Engenharia Agrícola e Ambiental, v.3, n.1, p.30-33, 1999.

RESENDE, R. S.; COELHO, R. D.; PIEDADE, S. M. S. Suscetibilidade de gotejadores ao entupimento de causa biológica. 2000. 17 f. Dissertação de Mestrado - Escola Superior de Agronomia "Luiz de Queiroz" - ESALQ, Piracicaba.

SAAD, J.C. C.; MARCUSSI, F. F.N. Distribuição da carga hidráulica em linhas de derivação otimizadas por programação linear. Engenharia Agrícola, v.26, n.2, p.406-414, 2006.

SILVA, E.M.; LIMA, J.E.F.W.; AZEVEDO, J.A.; RODRIGUES, L.N. Proposição de um modelo matemático para a avaliação do 
desempenho de sistemas de irrigação. Pesquisa

Agropecuária Brasileira, v.39, n.8, p.741-748, 2004.

TEIXEIRA, M. B. Efeitos de dosagens extremas de cloro e pH na vazão de gotejadores autocompensantes (irrigação localizada). 2006. 318 p. Tese (Doutorado)Escola Superior de Agricultura "Luiz de Queiroz" - ESALQ, Piracicaba.

VALNIR JÚNIOR, M.; CARVALHO, C. M. de;
SANTOS NETO, A. M. dos; SOARES, J. I.; LIMA, S. C. R. V.; CARVALHO, M. A. R. Análise de desempenho em laboratório de linha gotejadora antes e após sua utilização em campo. Revista Brasileira de Agricultura Irrigada, v. 5, n. 4, p. 351-360, 2011.

WERNECK, J.E. F.; Ferreira, R.S.A. \& CHRISTOFODIS, D. O uso da água para irrigação. 2009. Disponível em: http://www.cf.org.br/cf2004/irrigacao.doc Acesso em: 20 fev. 2012. 